\title{
Chapter 4 \\ Ecole des Mines de Paris: A Few Lessons from a Long History
}

\section{Armand Hatchuel}

I am honored that the organizers of this forum ${ }^{1}$ have asked me to present you with a short history of the Ecole des Mines de Paris. ${ }^{2}$ I'll have to be brief, but I would like to explain how we went from a Vocational Training School to a General Education School, then to a School based on Research, and how the image of engineers has changed over the last two centuries. The status of engineers as developed in France in the middle of the nineteenth century was invariably that of a scientist, but a scientist who also accepted explicit responsibility for his acts. The responsibility was progressively defined by three functions - critical, creative, and social — whose content and relative priorities have changed and will continue to change with the major movements in techniques, sciences, and society. ${ }^{3}$ For the Ecole des Mines de Paris, ${ }^{4}$ we will see that these functions have been reinterpreted over time. I will present a few ideas on what this long history may mean for us in the face of our contemporary challenges.

\footnotetext{
To appear in: Proceedings of the International Dean's Forum, "Creating talents for a new world" August 2015 Paris. Presses des Mines, 2017.

${ }^{1}$ This forum commemorated the School's move to Boulevard Saint-Michel in 1815.

${ }^{2}$ I would like to point out that I became interested in the history of engineers, and more particularly the history of this School, as a teacher of management sciences and as the co-director with Benoit Weil of the "Design theory and methods for innovation" chair.

${ }^{3}$ Our work exclusively deals with the history of civil mining engineers. A history of the functions of the Corps of Mining Engineers comes from a very different approach, especially given that, since the middle of the twentieth century, they have received training separate from that given to civil engineers. We could point out that they share the scientific identity of engineer with civil engineers, this being reinforced by prior training at Ecole Polytechnique for most of them.

${ }^{4}$ The Ecole des Mines de Paris is now known as MinesParisTech.
}
A. Hatchuel ( $\square)$
Chair of Design Theory and Methods for Innovation, MinesParisTech-PSL
Research University, Paris, France
e-mail: armand.hatchuel@mines-paristech.fr

E. Subrahmanian et al. (eds.), Engineering a Better Future, 


\section{A tradition of historical thinking}

History has often contributed to collective thinking and orientations at the School. In 1889, at a time of major reforms, Louis Aguillon, Professor of Law, was asked by the board that ran the School to draw up a landmark historical report. The School was one hundred years old and the road traveled appeared to have led far from the initial project, giving rise to questions as to the choices made. This is where the historian's work takes on its full value because, as Aguillon pointed out, "We can better explain the reason behind current things when we know what circumstances they were built upon." Since then, all the School's directors have supported historical thinking. ${ }^{5}$ The same holds true for the teachers at the School. ${ }^{6}$ But History cannot be studied without archives and without accessible documents, and the School has always benefited from a high-level library which has preserved an extraordinary wealth of materials - which is now available online.

As a reminder of some of the main chapters in the School's history, I will concentrate on how course content, pedagogical methods, the place of research, and views of "the engineer" have changed over time. ${ }^{7}$ I am thus in line with the subject of this forum which invites us to think about what the talents of the future will be. But it is also through pedagogical questions and the paradigms of the engineer that the School's unique history can dialogue with the international history of engineers and their training. These questions enable us to situate cultural and national particularities, both in terms of the exchanges that the School has benefited from and the influence it has had. They shed light on the challenges shared by all major scientific training programs today.

To simplify things, I will make a distinction between three periods in the history of the Ecole des Mines de Paris. The first period was that of the Professional Mining School. This period came to an end around 1890. But the Professional Mining School did not disappear, it became part of a Generalist School that sought to train engineers adapted to all sectors of industry and more importantly their evolution. ${ }^{8}$ At the end of the 1960s, this second School in turn became part of a School based on Research. This does not mean that scientific research only dates from that period, but rather that the School began to be organized around research centers designed to produce and transmit knowledge adapted to a world that is innovating faster than ever before.

\footnotetext{
${ }^{5}$ Please allow me to evoke the memory of Jacques Levy, who kindly encouraged my first research. ${ }^{6}$ I would notably point out the efforts made by our colleague Robert Mahl to diffuse this history. ${ }^{7}$ This text uses—in a different form — part of the material published in: A. Hatchuel, "La naissance de l'ingénieur généraliste: l'exemple de l'Ecole des Mines de Paris." Publication de l'Ecole des Mines 1997.

${ }^{8}$ In my 1997 study, ibid. Hatchuel 1997, I distinguish between two subsections in each of these periods. I spoke of a "widened professional model" between 1850 and 1900, and I made a distinction between a "sectoral general model" from 1900 to 1949 and a "universal general model" from 1949 to 1969. This text stopped in 1966, so I did not discuss the model of the School based on Research.
} 
Each period developed a richer, more open concept of engineers. Their scientific identity has constantly been reasserted, but we have become more aware of the multiple functions that they have to be prepared for. This evolution does not follow a brilliant, omniscient pedagogical plan. It is the result of hard choices and inventions made necessary by the history of the world and sciences that have always held surprises over these past two centuries.

The starting point gave no hints of such an evolution. Around 1750, the noble science was that of the engineer-architect and specialists in military and civil construction. In 1729, Forest de Belidor's work, "La Science des Ingénieurs" (The Science of Engineers), became the reference and was quickly translated into German.

Faced with this noble science, which was already highly mathematical and whose exploits were visible - inherited by the Ecole des Ponts et Chaussées - the art of mining lacked prestige. It was mainly based on practice, trade, and observation. Working conditions in the mines were difficult and unhealthy. And yet, at the time, Saxony had a wealth of mining activities and had set up a New School, the Bergakademie, in Freiberg, which was famous for its teaching of the Art of Mining. Here, France copied Germany and took inspiration from the Freiberg School to found the Ecole Royale des Mines in 1783.

In 1815, with the fall of France's First Empire and following a number of ups and downs, the Ecole des Mines de Paris moved into its current home on Boulevard Saint-Michel. But the teaching was still the same as when it was created and reflected its mission, which was to be a Professional Mining School.

\subsection{Professional Mining School: 1815-1890}

The curriculum included four main courses, each spread out over 2 years. Three courses were scientific: metallurgy, mineralogy and docimasy, and mineralogy and geology, and one Mine and Machine Operations course which was to have a long-lasting posterity. This course is precisely where the image and role of mining inspectors and engineers were framed and discussed.

The aim was to teach an enlightened, responsible Art of Mining, as the first function of the students was a critical function: it was a question of fighting against inefficient, unjustified processes, bad practices by mine concession holders who exploited their mines poorly and endangered miners' lives.

But academic training alone is not enough for this mission. For a full mastery of the Art of Mining, solid, varied experience in the field is needed. That is why travel-study periods were so important, sometimes taking students to distant mining areas, and during which they kept a precise, accurate journal. These journals are 
now a major part of the School's great heritage. ${ }^{9}$ What was the purpose of these trips? To discover the variety of mines and mining techniques from around the world, of course, but also to demonstrate, above and beyond their critical function, the students' real capacity to discover their social function in the difficult world of miners, which is not easily accessible and occupy the most foreign of regions. Thus, the School was right away involved in globalization.

The Professional School's mission appeared to be clear and well suited to France's domestic challenges. But new dilemmas appeared starting in 1850, requiring reflection.

First of all, there was a radical transformation in the art of mining itself, which led to a series of new basic sciences. Crystallography broke new ground in mineralogy. Thermodynamics, which is the science of transformations of energy and machines, shook up Bélidor's physics and required new mathematics. Chemistry, which is so important to the art of mining, underwent a revolution that changed all sciences. From then on, the traditional subjects taught at the School required a much higher general level in sciences, and this need was met by creating preparatory schools in mathematics, physics, and chemistry for the so-called "external" students, i.e., not from the Ecole Polytechnique.

Mining engineers continued to be people skilled in the Art, because each mine is unique. But they also shared the concept of the engineer, as an "applied scientist", which took hold during the same period. This identity contributed to engineers' especially high social standing in France. They benefited from an image as intellectuals with vast scientific culture compared with "the engineer" in the English-speaking countries, who maintained the image of a technician. ${ }^{10}$ Furthermore, this new identity gave the engineer's critical function a more asserted legitimacy: alongside the subtleties of training in the Art of Mining, their scientific knowledge enabled them to make thorough analyses of, and sometimes to challenge, existing procedures.

During this period, the engineer's creative function became clearer than it had been before: the function of industrial inventor. This is explained in the major reference work of the day, Laboulaye's dictionary of arts and manufactures: "The second degree of intellectual work is that of the engineer, the industrial inventor who, with a special purpose, applies acquired knowledge to industrial practices and every day creates new progress, new increased wealth."

This new concept oriented the School's subsequent choices, as events continued to arise that led the School, after long discussions, to add three courses that should be mentioned as they resolutely moved away from the initial professional model and foreshadowed the debates with which all engineering training programs were repeatedly to be confronted.

\footnotetext{
${ }^{9}$ For example, online you can read Edouard Sauvage's 1874 travel journal from his trip across America from East to West.

${ }^{10}$ This image is still very important in both the USA and the United Kingdom, with a multitude of campaigns designed to convince people that engineers are scientists.
} 


\section{New dilemmas and new courses}

The first of these courses was railways. Should this have been considered a completely different industry and not teach the fundamentals of this activity? After all, the railways were replacing the ships and coaches that the School did not cover in its curriculum. But it is also true that the railways used techniques that came directly from the mining business. Lastly, it was an act of national interest and its wide scope was to make it the leading employer of engineering graduates. The decision to introduce this course was a wise one, as can be seen in the many descendants that were to follow. But was it the School's role to provide training for all new activities in the industry? Railways were a generic activity, i.e., necessary to all the others and an amazing source of new inventions. A different choice was made later on concerning the automobile and aviation.

The second course that broke with the past was Law and Industrial Economy, which is an emanation/specialization in the Mining School's operating course. The School was concerned when it was introduced - political economy was a sensitive, contentious subject. But the major developments in social questions needed to be dealt with. Child labor was banned in 1841. Students needed to be made aware of their new legal responsibilities, but without dogmatism and maintaining an engineering point of view. Aguillon gave a reminder of this: "The council, considering that it is a question of applying political economy to mines and factories, was of the opinion that these lessons should be entrusted to an engineer who alone could understand the existing relations between mining laws and the questions of the art."

The third major course that gave rise to debates was Paleontology, which also lies on the edges of the professional model. During the first half of the nineteenth century, Natural History became a discipline that was inseparable from geological studies: Cuvier, Lamarck, and Lyell were famous, but here again there were many controversies, notably with the Church. There were careful attempts at a few conferences, then the idea of having a course was accepted, not without concerns: "It was feared that the School would be diverted from its destination by producing naturalists rather than engineers."11

These three examples were forerunners to the now recurring dilemmas facing all engineering training-how should we react to the emergence of new industries? How should we integrate changes in law, social doctrines, and engineers' responsibilities? To what extent should scientific progress and the appearance of new sciences be taken into account?

In response to this, the School appears to have forged a guiding principle for its approach to novelties. This consists in not integrating new fields until it is possible to absorb their content, to adapt them to needs or even to develop them in a direction that is of interest to the School. Far from freezing the program in time, this principle was to organize the transition from the Professional School toward a new model that we will call the Generalist School, which preserved the content from the Professional School while inserting it into a more universal program.

\footnotetext{
${ }^{11}$ Ibid. Aguillon 1889.
} 


\subsection{Generalist School: 1890-1967}

This transition had already begun to manifest itself in the 1870s when the effects of the second industrial revolution began to be felt, notably with the growing importance of industrial chemistry and the development of the science of electricity. Furthermore, the concept of the laboratory took hold as a teaching tool as well as progress in knowledge.

At the end of the 1880s, Henry le Chatelier developed the new "industrial chemistry" in his laboratory, which was his claim to fame. The opposite was true for electricity, for which there were just a few conferences and its main teaching was shoved off to the Machines course, which had replaced the mining operations course. At the same time, there was a trend among the main courses at the School to divide up into specializations: the geology course gave rise to a new branch with the Petrography course.

In 1885, the Legislation and Industrial Economy course separated into two courses. The new course was strongly influenced by the work of Frédéric Le Play, who invented social economy by developing his famous studies on working-class family life in Europe. This teaching was also linked to the development of the encouragement society in social economy, which had a strong influence on the industrials of the period.

At the end of the nineteenth century, the School appears to have been able to take a breath and contain the expansion of its subjects. Aguillon stated, "They wanted to stay within the specialties that explain and justify the existence of the Ecoles de Mines, they did not give into the temptation to appear to be teaching everything, with the risk of teaching students nothing." In 1900, the School's director, Carnot, also insisted, "The main goal of the reforms was to increase courses, in response to new branches in Industry... They avoided a general preparation that is necessarily insufficient for any career in industry and, conversely, they sought to delve as deeply as possible into all knowledge concerning the mineral industry...."

But history did not come to a halt, and it even started to speed up. Since 1890, the automobile and aviation industries had become an ever greater presence. What should be done? Once again, a few specialized conferences were attempted, but they did not repeat what had been done with the railways: there were no grand, special courses. A course in nonferrous metallurgy was created, however, in response to the needs of new industries.

Moreover, alongside the old legal questions, questions of industrial organization were increasingly on the table. With Henry Le Chatelier, the School gave an enthusiastic welcome to Frederick Taylor and Scientific Management. The idea of "industrial science" was already very present at the School and its extension to questions of labor and organization corresponded to a new scientific approach to the engineer's social function, which took off in the 1950s.

From 1920 to 1949, countless industrial and scientific innovations came to the School. The number of teaching programs increased considerably. The School was 
de facto a generalist school, but it had not yet accepted this in its mission statement, and it did not yet have pedagogical structures adapted to the expansion of this model.

\section{A new pedagogical model}

That came about in 1949, when the School no longer hesitated to take a position that was the opposite to that of 1900: "We can define the School's curriculum as a general technical curriculum." "The extremely fast evolution and development of industry - notably the mining and metallurgy industries-make it no longer possible to hope to delve in depth into all the major techniques and sciences that students may need." Furthermore, in the field, "engineers are confronted with much greater specialization than before...."

A new pedagogical model therefore had to be formulated for the future: "We will therefore prepare students for the range of specializations,... We will not sacrifice our training to the benefit of technology, ... we will not shirk a difficult compromise, ... and the focus will be on the work method,... and awareness of the mission of the future engineer."

This model gave rise to a new study structure which now had three levels:

(a) General scientific education including the classical sciences (math, physics, chemistry) as well as natural sciences in the mining tradition. This preserved the dual epistemology of modeling and observation.

(b) Training in generic technologies which, in principle, are found in all industries and which include law, economics, and scientific management.

(c) Lastly, options, which are specialized courses in which the School's educational traditions can be maintained: personalized tutoring, as well as teaching based on industrial internships and travel.

At the end of the 1960s, this model opened the door to new, original courses, but also to multiple options. It notably made it possible to imagine a new kind of engineer combining two mutually reinforcing identities:

- A scientific identity that is no longer just "applied" because they have to develop new sciences as well as new techniques and, for this, they must mobilize the most rigorous, most effective methods. These skills ensure their critical and creative functions.

- An identity as a modern manager because they have to take on their social function as organizers and managers in the business world based on the best scientific analyses of these questions.

This model corresponded relatively well to the needs of students after the events of May 1968. It also brought many young teachers to the School, who were to become the academic management of the new model of a School based on Research that absorbed the Generalist School, which was not sustainable over the long term without new resources and major institutional changes. 


\subsection{School Based on Research: 1967-2014 ${ }^{12}$}

We cannot talk about the institutional changes of the 70s and 80s without mentioning the influence of Pierre Laffitte. ${ }^{13}$ But his influence would have quickly eroded if it had not been supported by the State and renewed by his successors at the head of the School. ${ }^{14}$ What happened? Starting in the 1970s, the School undertook two interdependent changes:

(a) Implementation of a new academic model that included:

- The creation of its own doctoral program (1983) along with the development of many scientific masters degrees with universities. The curriculum followed by the students at the Ecole des Mines was equivalent to a Master of Science degree in the English-speaking countries. This program was truly successful as the School now trains nearly a hundred doctoral students each year.

- The creation of research and teaching centers in a wide variety of fields, including economics, management, and sociology.

(b) Definition of an original research strategy, called directed research, aimed at developing fundamental work based on industrial or societal problems.

This academic model consolidates collaboration between research and companies with the development of Armines, a private, not-for-profit operator in public research. The creation of the Sophia Antipolis technology park, for which we have Pierre Laffitte to thank, was also designed to encourage cooperation between science and development on a regional scale; the School played a major role.

With unwavering support from the State, ${ }^{15}$ these new institutions encourage the dynamism and flexibility of the new model of the School based on Research. The School has thus been able to: (i) attract scientific staff who establish stronger, faster links between training and research; (ii) quickly develop new disciplines and new research subjects ${ }^{16}$; (iii) support the strong expansion of collaboration with industry which is now a major share of its budget.

\footnotetext{
${ }^{12}$ I adopted the date of 2014, not as the end of the School based on Research, but rather because, that year, MinesParistech became a founding member of the PSL Research University community and this choice would affect its future history.

${ }^{13}$ To whom the School paid a warm tribute at the event celebrating his 90th birthday on April 16, 2015.

${ }^{14}$ Jacques Levy, Benoit Legait and Romain Soubeyran.

${ }^{15}$ Under the authority of the Ecole des Mines, formerly the Conseil Général des Mines, today the Conseil Général de l'Economie, de l'Industrie, de l'Energie et des Techniques Avancées (CGEIET).

${ }^{16}$ The School played a major role in training for new disciplines: Geostatistics, Earth Sciences, Computer Science, Energetics, Scientific Management, Sociology of Innovation, Digital Economy, Design Theory, Logistics and Production Systems, Hazard Sciences and Quantitative Finance, etc.
} 
This model also brings new representations of engineers. Alongside the image of a scientist-manager, the engineer's creative function is once again emphasized along with that of the designer and innovator scientist, and the scientist-entrepreneur. Thus, at the start of the 1990s, under the influence of Gilbert Frade, the School created the "entrepreneurial act", inviting all students to develop their ability to take initiatives through personal projects.

The School also introduced several research programs and original teaching in the fields of design, entrepreneurship, and innovation, some of which have become famous in France and abroad.

\subsection{What Should We Take Away from This Long History? Contemporary Challenges and New Images of the Engineer}

Many lessons can always be learned from such a long, event-filled history. First of all, I think the School has learned values and principles that have been implemented and are widely shared:

On the pedagogical level:

- Training for engineers is not just a matter of transfer of knowledge and also includes an educational project.

- Pedagogical methods must maintain dual epistemology: on the one hand, there is mathematical modeling, on the other, there is observation, experience, entrepreneurship, and travel.

- Training for engineers cannot be isolated, it must maintain symbiotic relations with other forms of education, with business sciences, economics, and society, but also with Art and Medical Schools.

- We need to increase awareness of the historical reality among our students: for two centuries, the concept of what an engineer is has evolved; it is still strongly marked by national cultures, but history also testifies to influences crossing from one culture to another.

On the academic level:

- Scientific research should be at the heart of training for engineers.

- It must be flexible and robust because the School needs to quickly develop new disciplines, but always based on solid scientific foundations to avoid academic and media bubbles.

- Research adapted to engineering training must be collaborative to a large extent, because engineers' mission is to deal with problems that arise in industry and in society, and also because fundamental discoveries sometimes arise from original studies of these questions. Furthermore, history has shown that, by cooperating 
closely with companies, public authorities, and other university programs, the School has been able to foresee several major transformations and to prepare its students.

\section{- And tomorrow?}

Are these principles still useful in the face of the major challenges awaiting us? We think so. These challenges concern all universities and, as in the past, the School will profit from following the most interesting initiatives developed in the developed world and in emerging countries. Personally, I will insist on three of these challenges.

First challenge: the globalization in higher education is an invitation for the School to take its place in the "global village" of the university system. The School has chosen to do this by joining the PSL community. ${ }^{17}$ All the PSL establishments place great importance on the link between training and research and this point is crucial, because the engineers we train must remain high-level scientists. Furthermore, the cycle between the creation of knowledge and the development of innovations which is of interest for engineer training will continue to shrink. ${ }^{18}$

Second challenge: the digital revolution is shaking up our own operations as much as those of our industrial and social partners. What teaching will we dispense tomorrow? How will companies operate tomorrow? We can think about this alone, but we are convinced that by maintaining strong collaborative research we will invent original forms of initial training and continuing education. As for many other revolutions over the past two centuries, the School will have to be a significant player in these transformations.

Third challenge: there is no denying that our times are marked by an accumulation of environmental and social crises and imbalances. The excesses of financial capitalism, the increase in social inequalities, the environmental and climate threats, the political chaos that reigns in many countries, etc. Over more than two centuries of existence, the School has been confronted with many difficult situations. All we need to do is to mention its date of birth-1783 - to remember that, from the start, the School went through a particularly critical period in the history of the country and the world. We have every reason to believe that, as it has done in the past, it will have to participate in producing new models for training engineers. This effort will go through scientific, political, and institutional revolutions in which the School will have to play an inventive role. On the road forward, there are a few lessons from its long history that can serve as guides.

It is aware that the scientific training that engineers require entails close work with research. The School has also learned that the identity of its engineers is constituted through the three functions-critical, creative, and social-that we

\footnotetext{
${ }^{17}$ PSL Research University is a group of establishments set up under France's new laws and guidelines.

${ }^{18}$ MinesParisTech also has an association agreement with Institut Mines-Telecom, which falls under the same authority at the Ministry of the Economy: The Conseil Général de l'Economie, de l'Industrie, de l'Energie et des Techniques Avancées. Lastly, the School is a member of ParisTech.
} 
mentioned above. But what content will these functions have in the future? Will others have to be recognized and will students have to be prepared for them? The importance of collective thinking on these points cannot be underestimated. On this subject, all I can do is to make a few suggestions based on work carried out at the School. $^{19}$

(a) In a world dominated by the rules of financial capitalism, it seems to me that the new critical function of engineers lies in their ability to resist the primacy of short-term financial logic alone. They can legitimately embody the value of productive investment and the need for radical innovation, whether private or public. Faced with the contemporary fears raised by a science that appears to be too blind to its own consequences, they can also try to demonstrate that the scientific approach can be oriented toward collective progress.

(b) Since the beginning of the digital revolution, engineers have been increasingly called upon to act as scientists who innovate by designing new techniques and new usages, and, more often than in the past, to create businesses. The new creative function thus seems to me to lie in developing robust, sustainable innovation, and design methods that are up to the huge challenges of preserving the planet.

(c) Engineers' new social function is the product of these last two functions. It is thus a question of developing more participative and more inclusive forms of work, notably for the conduct and completion of complex, innovative projects. The task is all the more demanding in that these projects are usually carried out at globalized companies and will call for the intervention of many entities (subsidiaries, partners, associations, public authorities, etc.) in different countries and cultures. Some one hundred years ago, thanks to the scientific approach to organizations and to work, engineers contributed to an industry that is more attentive to its personnel. Today, they also have to think of ways to limit the abuses of globalized firms by improving the legal frameworks and standards that govern them. At the end of the nineteenth century, engineers played an essential role in the formation of modern companies. They must continue to pursue this mission today by participating in creating more responsible businesses, including in the poorest countries. Furthermore, as in the past, the School will have to respond to the humanistic aspirations of its students and society by adapting to their contemporary and future content.

These proposals have no pretention of being exhaustive. Moreover, new, heretofore unknown priorities are sure to arise. That is one of the most certain lessons of history. But along the lines that we have discussed, the Ecole des Mines in 2015 is on the right road.

\footnotetext{
${ }^{19}$ Notably at the Economics, Business and Society Department. And more particularly, concerning my own research, at the Scientific Management Center.
} 
Open Access This chapter is licensed under the terms of the Creative Commons Attribution 4.0 International License (http://creativecommons.org/licenses/by/4.0/), which permits use, sharing, adaptation, distribution and reproduction in any medium or format, as long as you give appropriate credit to the original author(s) and the source, provide a link to the Creative Commons license and indicate if changes were made.

The images or other third party material in this chapter are included in the chapter's Creative Commons license, unless indicated otherwise in a credit line to the material. If material is not included in the chapter's Creative Commons license and your intended use is not permitted by statutory regulation or exceeds the permitted use, you will need to obtain permission directly from the copyright holder.

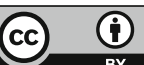

